\title{
C-Reactive Protein to Albumin Ratio Predicts Survival in Patients with Unresectable Hepatocellular Carcinoma Treated with Lenvatinib: A Multicenter Analysis
}

Toshifumi Tada ( $\nabla$ tadat0627@gmail.com )

Himeji Red Cross Hospital

Takashi Kumada

Gifu Kyoritsu University

Atsushi Hiraoka

Ehime Prefectural Central Hospital

Masashi Hirooka

Ehime University

Kazuya Kariyama

Okayama City Hospital

Joji Tani

Kagawa University

Masanori Atsukawa

Nippon Medical School

Koichi Takaguchi

Kagawa Prefectural Central Hospital

Ei Itobayashi

Asahi General Hospital

Shinya Fukunishi

Osaka Medical College

Kunihiko Tsuji

Teine Keijinkai Hospital

Toru Ishikawa

Saiseikai Niigata Hospital

Kazuto Tajiri

Toyama University Hospital

Hironori Ochi

Matsuyama Red Cross Hospital

Satoshi Yasuda

Ogaki Municipal Hospital 


\section{Hidenori Toyoda}

Ogaki Municipal Hospital

\section{Takeshi Hatanaka}

Gunma Saiseikai Maebashi Hospital

\section{Satoru Kakizaki}

National Hospital Organization Takasaki General Medical Center

\section{Noritomo Shimada}

Otakanomori Hospital

\section{Kazuhito Kawata}

Hamamatsu University School of Medicine

\section{Takaaki Tanaka}

Ehime Prefectural Central Hospital

\section{Hideko Ohama}

Osaka Medical College

\section{Kazuhiro Nouso}

Okayama City Hospital

\section{Asahiro Morishita}

Kagawa University

\section{Akemi Tsutsui}

Kagawa Prefectural Central Hospital

\section{Takuya Nagano}

Kagawa Prefectural Central Hospital

\section{Norio Itokawa}

Nippon Medical School

\section{Tomomi Okubo}

Osaka Medical College

\section{Taeang Arai}

Nippon Medical School

\section{Michitaka Imai}

Saiseikai Niigata Hospital

\section{Atsushi Naganuma}

National Hospital Organization Takasaki General Medical Center

\section{Tomoko Aoki}

Kindai University

\section{Yohei Koizumi}

Ehime University

\section{Shinichiro Nakamura}

Himeji Red Cross Hospital

Kouji Joko 
Matsuyama Red Cross Hospital

\section{Yoichi Hiasa}

Ehime University

Masatoshi Kudo

Kindai University

\section{Research Article}

Keywords: Ienvatinib, hepatocellular carcinoma, C-reactive protein to albumin ratio, survival

Posted Date: November 18th, 2021

DOl: https://doi.org/10.21203/rs.3.rs-1034239/v1

License: (c) (1) This work is licensed under a Creative Commons Attribution 4.0 International License. Read Full License 


\section{Abstract}

We investigated the impact of C-reactive protein to albumin ratio (CAR) on predicting outcomes in 522 patients with unresectable hepatocellular carcinoma (HCC) treated with lenvatinib. We determined the optimal CAR cutoff value with time-dependent receiver operating characteristic curve analysis.

Additionally, we clarified the relationship between CAR and liver function or HCC progression. Median overall survival was 20.0 (95\% confidence interval (Cl), 17.2-22.6) months. The optimal CAR cutoff value was determined to be 0.108 . Multivariate analysis showed that high CAR $(\geq 0.108)$ (hazard ratio (HR), $1.915 ; 95 \% \mathrm{Cl}, 1.495-2.452)$, Eastern Cooperative Oncology Group performance status $\geq 1$ (HR, 1.429), and a-fetoprotein $\geq 400 \mathrm{ng} / \mathrm{mL}(\mathrm{HR}, 1.604)$ were independently associated with overall survival. Cumulative overall survival differed significantly between patients with low versus high CAR $(p<0.001)$. Median progression-free survival was $7.5(95 \% \mathrm{Cl}, 6.7-8.1)$ months. Multivariate analysis showed that age, $C A R \geq 0.108$ (HR, 1.644; 95\% Cl, 1.324-2.043), and non-hepatitis $B$, non-hepatitis C etiology (HR, 0.726 ) were independently associated with progression-free survival. Cumulative progression-free survival differed significantly between patients with low versus high CAR $(p<0.001)$. CAR values were significantly higher as Japan Integrated Staging score increased $(p<0.001)$. In conclusion, CAR can predict outcomes in patients with unresectable HCC treated with lenvatinib.

\section{Introduction}

Hepatocellular carcinoma (HCC) is the most commonly encountered primary liver malignancy and the sixth most common malignant disease in the world [1]. Surgical resection, liver transplantation, and local ablation therapy are indicated for early-stage HCC [2]. For patients with intermediate and advanced HCC, transarterial chemoembolization and systemic therapies such as targeted therapy or immunotherapy are usually recommended [2].

Sorafenib, a molecularly targeted agent, has been developed for first-line systemic treatment of patients with unresectable HCC [3, 4]. In 2018, lenvatinib [5], a newly developed tyrosine kinase inhibitor, became available in Japan as first-line therapy in patients with unresectable HCC. More recently in Japan, the combination of atezolizumab plus bevacizumab has been approved as first-line systemic therapy in patients with unresectable HCC [6].

Various clinical markers such as age, sex, Eastern Cooperative Oncology Group performance status (ECOG-PS), a-fetoprotein, hepatic function, hepatic fibrosis, and HCC stage have been reported as predictors of survival in patients who underwent treatment for HCC [1, 7-10]. However, characteristics associated with survival in patients with unresectable HCC treated with lenvatinib have not been sufficiently investigated.

High C-reactive protein (CRP) to albumin ratio (CAR) has been reported to be associated with poor outcomes in numerous malignancies [11-16]. This predictor of systemic inflammation is easy and inexpensive to measure [11-16]. Several reports have suggested that elevated pretreatment CAR might be 
associated with poor outcomes in patients with $\mathrm{HCC}$ treated with resection, radiofrequency ablation, or transarterial chemoembolization $[15,16]$. However, the association between CAR and prognosis in patients with unresectable HCC treated with molecularly targeted agents, especially lenvatinib, has not been studied.

In this study, we investigated the impact of CAR on predicting overall survival and progression-free survival in patients with unresectable HCC treated with lenvatinib using clinical data from multiple Japanese centers specializing in liver disease.

\section{Results}

\section{Patient characteristics}

The baseline characteristics of the 522 study patients are summarized in Table 1 . There were 112 $(21.5 \%)$ females and $410(78.5 \%)$ males with a median age of 73.0 (68.0-79.0) years. Median CAR was $0.079(0.027-0.254)$. There were $5(1.0 \%)$ patients with Japan Integrated Staging (JIS) score 0,88 (16.9\%) patients with JIS score 1, 197 (37.7\%) patients with JIS score 2, 226 (43.3\%) patients with JIS score 3 , and 6 (1.1\%) patients with JIS score 4. Median follow-up was 13.3 (7.0-22.6) months. Table 1 also lists the baseline characteristics of the 522 study patients stratified by CAR level.

\section{Overall survival and progression-free survival}

Figure 1a shows the curve for overall survival in the study patients. Median overall survival was 20.0 (95\% confidence interval [Cl], 17.2-22.6) months. Figure $1 \mathrm{~b}$ shows the curve for progression-free survival in the study patients. Median progression-free survival was $7.5(95 \% \mathrm{Cl}, 6.7-8.1)$ months.

Figure 2 shows the receiver operating characteristic (ROC) curve for CAR with overall survival at 20 months after the start of follow-up based on time-dependent ROC analysis. The optimal CAR cutoff value was determined to be 0.108 based on the Youden index.

\section{Therapeutic response}

Radiological best response rates for complete response, partial response, stable disease, and progressive disease were 5.0\% (24/481), 37.0\% (178/481), 39.3\% (189/481), and 18.7\% (90/481), respectively. Therapeutic response was not evaluated in 41 patients. The overall response rate was $42.0 \%$ and the disease control rate was $81.3 \%$ (Table 1 ). Therapeutic responses stratified by CAR are also listed in Table 1. ORR was significantly different between patients with low CAR and high CAR $(p=0.039)$.

\section{Factors associated with overall survival}

Factors associated with overall survival in the univariate analysis are listed in Table 2. The following variables were statistically significant: ECOG-PS, a-fetoprotein, extrahepatic spread, history of sorafenib therapy, and CAR. 
Multivariate Cox proportional hazards modeling with the covariates of age, sex, ECOG-PS, etiology, afetoprotein, macroscopic vascular invasion, extrahepatic spread, history of sorafenib therapy, and CAR showed that ECOG-PS $\geq 1$ (hazard ratio (HR), 1.429; $95 \% \mathrm{Cl}, 1.075-1.899 ; \mathrm{p}=0.014$ ), $\mathrm{a}$ fetoprotein $\geq 400 \mathrm{ng} / \mathrm{mL}(\mathrm{HR}, 1.604 ; 95 \% \mathrm{Cl}, 1.237-2.079 ; \mathrm{p}<0.001)$, and CAR $\geq 0.108$ (HR, 1.915; 95\% Cl, $1.495-2.452 ; \mathrm{p}<0.001$ ) were independently associated with overall survival (Table 2 ).

\section{Factors associated with progression-free survival}

Factors associated with progression-free survival in the univariate analysis are listed in Table 3. Etiology and CAR were statistically significantly associated with progression-free survival.

Multivariate Cox proportional hazards modeling with the covariates of age, sex, ECOG-PS, etiology, afetoprotein, macroscopic vascular invasion, extrahepatic spread, history of sorafenib therapy, and CAR showed that non-hepatitis $B$, non-hepatitis $C$ etiology $(\mathrm{HR}, 0.726 ; 95 \% \mathrm{Cl}, 0.583-0.905 ; \mathrm{p}=0.004)$ and $C A R \geq 0.108(H R, 1.644 ; 95 \% \mathrm{Cl}, 1.324-2.043 ; p<0.001)$ were independently associated with progression-free survival (Table 3 ).

\section{Overall survival and progression-free survival stratified by CAR}

Figure 3a shows the curves for overall survival stratified by CAR. Median overall survival was $27.2(95 \% \mathrm{Cl}, 21.7-31.6)$ months in patients with low CAR (<0.108) and $13.3(95 \% \mathrm{Cl}, 10.1-15.7)$ months in patients with high CAR $(\geq 0.108)$, respectively $(p<0.001)$.

Figure $3 \mathrm{~b}$ shows the curves for progression-free survival stratified by CAR. Median progression-free survival was $8.8(95 \% \mathrm{Cl}, 7.8-11.2)$ months in patients with low CAR $(<0.108)$ and $5.6(95 \% \mathrm{Cl}, 4.5-6.8)$ months in patients with high CAR $(\geq 0.108)$, respectively $(p<0.001)$.

\section{Relationship between clinical markers and CAR}

Figure 4a shows the relationship between Child-Pugh score and CAR. CAR values were significantly higher as Child-Pugh score increased $(p<0.001)$. Figure $4 b$ shows the relationship between the presence or absence of macroscopic vascular invasion and CAR. CAR values were significantly different between patients with versus without macroscopic vascular invasion $(p=0.001)$. Figure $4 c$ shows the relationship between the presence or absence of extrahepatic spread and CAR. CAR values were significantly different between patients with versus without extrahepatic spread $(p=0.008)$.

Figure $4 \mathrm{~d}$ shows the relationship between JIS score and CAR. CAR values were significantly higher as JIS score increased $(p<0.001)$.

\section{Discussion}

In this multicenter study, patients with unresectable HCC and treated with lenvatinib who had high CAR had poorer outcomes than patients with low CAR. Multivariate analysis with adjustment for age, sex, 
ECOG-PS, etiology, a-fetoprotein, macroscopic vascular invasion, extrahepatic spread, history of sorafenib therapy, and CAR showed that CAR is independently associated with overall survival and progression-free survival. In addition, multivariate analysis showed that ECOG-PS and a-fetoprotein are also independently associated with overall survival. Multivariate analysis showed that etiology is also independently associated with progression-free survival. Furthermore, CAR values were significantly higher as JIS score, a useful prognostic factor for HCC, increased. These results suggest that CAR can predict both overall survival and progression-free survival in patients with unresectable HCC treated with lenvatinib. In addition, CAR, a biomarker that is easy and inexpensive to measure, is an integrated marker that reflects hepatic function and HCC stage.

CAR has been investigated as an indicator in digestive malignancies such as esophageal, gastric, colorectal, and pancreatic cancer [11-14]. In HCC, the impact of CAR on survival and recurrence has been reported in patients with HCC treated with surgical resection, radiofrequency ablation, transarterial chemoembolization, or molecularly targeted therapy $[15,16]$. Oh et al. [15] investigated the relationship between CAR and outcomes in 389 patients who underwent resection for HCC. They found that a postoperative CAR increase of 1.0 is associated with a 1.171-fold decrease in overall survival (HR, 1.171; $95 \% \mathrm{Cl}, 1.072-1.278 ; p<0.001)$ and a 1.19 -fold decrease in progression-free survival $(\mathrm{HR}, 1.190 ; 95 \% \mathrm{Cl}$, $1.108-1.278 ; p<0.001)$ in multivariate analysis [15]. They also found that the optimal CAR cutoff values for predicting overall survival and progression-free survival were 0.625 and 0.500 , respectively, using ROC curve analysis [15]. Kinoshita et al. [16] investigated the relationship between CAR and overall survival in 186 patients with $\mathrm{HCC}$ treated with resection, locoregional treatment, transarterial chemoembolization, sorafenib therapy, or best supportive care. They found that CAR $\geq 0.037(\mathrm{HR}, 3.394 ; 95 \% \mathrm{Cl}, 1.986-5.801$; $p<0.001)$ was independently associated with worse overall survival in their cohort by multivariate analysis [16]. They determined the optimal CAR cutoff value for predicting overall survival was 0.037 with ROC curve analysis [16]. In this study, we also found that CAR is significantly associated with both overall survival and progression-free survival in multivariate analyses using data obtained from patients with HCC treated lenvatinib, a molecularly targeted agent. An advantage of our study in comparison with the previous studies $[15,16]$ is that we determined the optimal CAR cutoff value using time-dependent ROC curve analysis for overall survival obtained with the Kaplan-Meier method, not simple ROC curve analysis (i.e., with binary values for survival and death). Another advantage of our study relative to the previous study [16] is that this study included a large number of patients with HCC treated with lenvatinib, instead of various treatments for HCC.

Accumulating evidence from previous reports indicates that inflammation and malignancy are related. Several mechanisms have been reported for the relationship between inflammatory response and malignancy: (i) tumor growth or invasion could induce tissue inflammation; (ii) necrosis of tumor and hypoxia or local tissue damage might activate an inflammatory response; and (iii) cancer cells, tumorrelated leukocytes, or both could induce the production of inflammatory cytokines, such as necrosis factor of tumor, interleukin (IL)-1, IL-6, and IL-8, and vascular endothelial growth factor. These inflammatory cytokines and chemokines facilitate cancer growth, invasion, angiogenesis, metastasis, subversion of the host immune response, and resistance to cytotoxic drugs [17-19]. Among clinical 
markers of inflammation, CRP is an acute-phase reactant synthesized by hepatocytes that is regulated by proinflammatory cytokines, particularly IL-6 [20]. Additionally, the presence of a systemic inflammatory response, evidenced by an elevation of CRP levels, accompanies a decrease in serum albumin concentrations and progressive loss of weight and lean tissue, resulting in poorer ECOG-PS and higher mortality in patients with malignancy $[21,22]$. This is of particular concern in patients with HCC, given the concomitant underlying illness and possible impaired nutritional status attributed to cirrhosis [23]. In this study, we clarified that high CAR is associated with poor liver function and high tumor burden, such as macroscopic vascular invasion or extrahepatic spread, in patients with HCC treated with a molecularly targeted agent.

The main limitations of present study included its hospital-based subjects and retrospective nature. Although this study included a large number of patients with HCC from multiple liver centers in Japan, further prospective studies with community-based participants and long-term follow-up are warranted. Another limitation of present study was that treatment of HCC after lenvatinib therapy was not analyzed. Because treatment after lenvatinib therapy for HCC might affect prognosis, further studies that include the analysis of HCC treatment after lenvatinib therapy are warranted.

In conclusion, CAR, a marker that is easy and inexpensive to measure, can predict outcomes in patients with unresectable HCC treated with lenvatinib. In addition, CAR is associated with liver function and HCC progression. Further studies are warranted to confirm these findings in other populations.

\section{Materials And Methods}

\section{Patients}

The study protocol was approved by the institutional ethics committee of Ehime Prefectural Central Hospital (IRB No. 30-66) based on the Guidelines for Clinical Research issued by the Ministry of Health, Labour and Welfare of Japan.

We enrolled 720 patients with unresectable HCC who received lenvatinib between March 2018 and July 2021 at 20 institutions in Japan. Of these, 522 met the following eligibility criteria: (1) treatment with lenvatinib for more than 2 weeks, (2) follow-up duration of greater than 4 weeks, (3) Child-Pugh class A or B disease, and (4) data available on CAR at the start of follow-up (Figure 5). CAR was calculated by dividing the CRP level by the albumin level.

We collected clinical data at the start of lenvatinib therapy from the medical records of these 522 patients. The start of follow-up was defined as the date when lenvatinib therapy began. The end of follow-up was defined as the date of the final visit for patients who remained alive or the date of death for patients who died during follow-up.

The etiology of HCC was considered to be hepatitis B virus in patients positive for hepatitis B virus surface antigen. It was considered to be hepatitis $C$ virus in patients positive for hepatitis $C$ virus 
antibodies.

\section{Diagnosis and treatment of HCC}

HCC was diagnosed based on increases in a-fetoprotein levels, pathological findings, or imaging findings in modalities such as dynamic computed tomography, magnetic resonance imaging, and contrastenhanced ultrasonography with perflubutane [24, 25]. To evaluate tumor progression, we used Barcelona Clinic Liver Cancer (BCLC) [26] and tumor node metastasis (TNM) staging, determined according to the 6th edition of TNM staging guidelines for HCC by the Liver Cancer Study Group of Japan (LCSGJ) (TNMLCSGJ) [27]. In addition, we used the JIS system for HCC prognosis [28]. We assessed liver function using the Child-Pugh classification system [29].

The most appropriate treatment modality for HCC in each patient was selected through discussion between surgeons, hepatologists, and radiologists in each institution, based on Japanese practice guidelines for $\operatorname{HCC}[30,31]$.

\section{Lenvatinib treatment and adverse events}

After obtaining written informed consent from each patient, lenvatinib (Lenvima ${ }^{\circ}$; Eisai, Tokyo, Japan) treatment was started. The dose of oral lenvatinib was $8 \mathrm{mg} /$ day in patients who weighed $<60 \mathrm{~kg}$ and $12 \mathrm{mg} /$ day in patients who weighed $\geq 60 \mathrm{~kg}$. However, in patients with advanced age, non-ChildPugh A disease, low body weight, and pleural effusion, ascites, or gastrointestinal varices with a risk of bleeding, the initial dose of lenvatinib was reduced at the discretion of the physician.

Lenvatinib was discontinued when any unacceptable or serious adverse event or clinical tumor progression occurred. In accordance with the drug manufacturer's guidelines, the dose was reduced or treatment was interrupted when a patient developed any grade $\geq 3$ severe adverse events or if any unacceptable treatment-related adverse events occurred. Adverse events were assessed using the National Cancer Institute Common Terminology Criteria for Adverse Events, version 5.0 [32]. If a treatment-related adverse event occurred, dose reduction or temporary interruption occurred until the symptom resolved to grade 1 or 2 , based on the manufacturer's guidelines.

\section{Evaluation of therapeutic response}

Local physicians at each institution evaluated tumors using enhanced computed tomography or magnetic resonance imaging at 4 or 12 weeks after introducing lenvatinib, in accordance with the modified Response Evaluation Criteria in Solid Tumors [33, 34].

\section{Statistical analysis}

Continuous variables are expressed as medians (interquartile range). The Mann-Whitney U-test was used for continuous variables. The $\chi^{2}$-test or Fisher's exact test was used for categorical variables. In addition, the Jonckheere-Terpstra test was used to analyze trends between CAR values and clinical markers. 
Actuarial analysis of cumulative overall survival and progression-free survival was performed using the Kaplan-Meier method, and differences were assessed with the log-rank test. Univariate and multivariate Cox proportional hazards models were used for analysis of factors related to overall survival and progression-free survival.

Time-dependent ROC curves for overall survival were obtained with the Kaplan-Meier method by CAR [35]. We determined the cutoff value for CAR at the median overall survival of this study cohort using the maximum Youden index (sensitivity+specifcity-1) [36]. In this study, we used age of 75 years and afetoprotein of $400 \mathrm{ng} / \mathrm{mL}$ as cutoff values for analysis based on previous report [37].

Statistical significance was defined as $p<0.05$. Statistical analyses were performed with EZR Ver. 1.53 (Saitama Medical Center, Jichi Medical University, Saitama, Japan), which is a graphical user interface for R (The R Foundation for Statistical Computing, Vienna, Austria) [38]. More precisely, it is a modified version of the $\mathrm{R}$ commander designed to add statistical functions frequently used in biostatistics.

\section{Abbreviations}

HCC, hepatocellular carcinoma; ECOG-PS, Eastern Cooperative Oncology Group performance status; CRP, C-reactive protein; CAR, C-reactive protein to albumin ratio; BCLC, Barcelona Clinic Liver Cancer; TNM, tumor node metastasis; LCSGJ, Liver Cancer Study Group of Japan; JIS, Japan Integrated Staging; ROC, receiver operating characteristic; $\mathrm{Cl}$, confidence interval; $\mathrm{HR}$, hazard ratio; IL, interleukin.

\section{Declarations}

\section{Acknowledgments}

Funding: None to declare.

\section{Conflicts of interest:}

Takashi Kumada, MD, PhD: lecture fees from Eisai.

Atsushi Hiraoka, MD, PhD: lecture fees from Bayer, Eisai, Eli Lilly, and Otsuka.

Masatoshi Kudo, MD, PhD: advisory role at Eiasi, Ono, MSD, Bristol-Myers Squibb, and Roche; lecture fees from Eisai, Bayer, MSD, Bristol-Myers Squibb, Eli Lilly, and EA Pharma; and research funding from Gilead Sciences, Taiho, Sumitomo Dainippon Pharma, Takeda, Otsuka, EA Pharma, AbbVie, and Eisai.

None of the other authors have potential conflicts of interest to declare.

Availability of data and material: The datasets are available from the corresponding author on reasonable request.

\section{Authors' contributions}


TTad, HA, and TK conceived the study and participated in its design and coordination. TTad, AH, TK, MH, KKar, JT, MA, KTak, El, SF, KTs, TI, KTaj, HOc, SY, HT, TH, SK, NS, KKaw, TTan, HOh, KN, AM, AT, TNa, NI, TO, $\mathrm{TaA}, \mathrm{MI}, \mathrm{AN}, \mathrm{ToA}, \mathrm{YK}, \mathrm{SN}, \mathrm{KJ}, \mathrm{YH}$, and MK performed data curation. TTad performed statistical analyses and interpretation. TTad, $\mathrm{AH}, \mathrm{TH}, \mathrm{HT}$, and TK drafted the manuscript.

\section{All authors have read and approved the final version of the manuscript.}

Ethics approval: The protocol used in the present study was approved by the Institutional Ethics Committee of Ehime Prefectural Central Hospital (IRB No. 30-66), based on the Guidelines for Clinical Research issued by the Ministry of Health and Welfare of Japan. All methods were carried out in accordance with relevant guidelines and regulations.

Consent to participate: Written informed consent was obtained from each patient.

Consent for publication: Written informed consent was obtained from each patient.

\section{References}

1. Murad MH, Marrero JA. AASLD guidelines for the treatment of hepatocellular carcinoma. Hepatology. 67, 358-380 (2018).

2. Llovet JM, et al; AASLD Panel of Experts on Trial Design in HCC. Trial Design and Endpoints in Hepatocellular Carcinoma: AASLD Consensus Conference. Hepatology. 73 Suppl 1, 158-191 (2021).

3. Llovet JM, et al; SHARP Investigators Study Group. Sorafenib in advanced hepatocellular carcinoma. N Engl J Med. 359, 378-390 (2008).

4. Cheng AL, et al. Safety and efficacy of sorafenib in patients in the Asia-Pacific region with advanced hepatocellular carcinoma: a phase III randomised, double-blind, placebo-controlled trial. Lancet Oncol. 10, 25-34 (2009).

5. Kudo $M$, et al. Lenvatinib versus sorafenib in first-line treatment of patients with unresectable hepatocellular carcinoma: a randomised phase 3 non-inferiority trial. Lancet. 391, 1163-1173 (2018).

6. Finn RS, et al; IMbrave150 Investigators. Atezolizumab plus Bevacizumab in Unresectable Hepatocellular Carcinoma. N Engl J Med. 382, 1894-1905 (2020).

7. Tada $T$, et al. Impact of the branched-chain amino acid to tyrosine ratio and branched-chain amino acid granule therapy in patients with hepatocellular carcinoma: A propensity score analysis. $\mathrm{J}$ Gastroenterol Hepatol. 30, 1412-1419 (2015).

8. Toyoda $\mathrm{H}$, et al. Differences in the impact of prognostic factors for hepatocellular carcinoma over time. Cancer Sci. 108, 2438-2444 (2017).

9. Toyoda $\mathrm{H}$, et al. Tumor Markers for Hepatocellular Carcinoma: Simple and Significant Predictors of Outcome in Patients with HCC. Liver Cancer. 4, 126-136 (2015).

10. Toyoda H, Kumada T, Tada T, Kaneoka Y, Maeda A. A laboratory marker, FIB-4 index, as a predictor for long-term outcomes of hepatocellular carcinoma patients after curative hepatic resection. 
Surgery. 157, 699-707 (2015).

11. Xu XL, Yu HQ, Hu W, Song Q, Mao WM. A Novel Inflammation-Based Prognostic Score, the C-Reactive Protein/Albumin Ratio Predicts the Prognosis of Patients with Operable Esophageal Squamous Cell Carcinoma. PLoS One. 10, e0138657 (2015).

12. Toiyama Y, et al. Clinical Burden of C-Reactive Protein/Albumin Ratio Before Curative Surgery for Patients with Gastric Cancer. Anticancer Res. 36, 6491-6498 (2016).

13. Ishizuka M, et al. Clinical Significance of the C-Reactive Protein to Albumin Ratio for Survival After Surgery for Colorectal Cancer. Ann Surg Oncol. 23, 900-907 (2016).

14. Haruki K, et al. The C-reactive Protein to Albumin Ratio Predicts Long-Term Outcomes in Patients with Pancreatic Cancer After Pancreatic Resection. World J Surg. 40, 2254-2260 (2016).

15. Oh TK, C et al. The High-Sensitivity C-Reactive Protein/Albumin Ratio Predicts Long-Term Oncologic Outcomes after Curative Resection for Hepatocellular Carcinoma. J Clin Med. 7, 139 (2018).

16. Kinoshita A, et al. The C-reactive protein/albumin ratio, a novel inflammation-based prognostic score, predicts outcomes in patients with hepatocellular carcinoma. Ann Surg Oncol. 22, 803-810 (2015).

17. Heikkila K, Ebrahim S, Lawlor DA. A systematic review of the association between circulating concentrations of C reactive protein and cancer. J Epidemiol Community Health. 61, 824-33 (2007).

18. Mantovani A, Allavena P, Sica A, Balkwill F. Cancer-related inflammation. Nature. 454, 436-444 (2008).

19. Elinav E, et al. Inflammation-induced cancer: crosstalk between tumours, immune cells and microorganisms. Nat Rev Cancer. 13, 759-771 (2013).

20. Morris-Stiff G, Gomez D, Prasad KR. C-reactive protein in liver cancer surgery. Eur J Surg Oncol. 34, 727-729 (2008).

21. McMillan DC. The systemic inflammation-based glasgow prognostic score: a decade of experience in patients with cancer. Cancer Treat Rev. 39, 534-540 (2013).

22. Park EJ, et al. Dietary and genetic obesity promote liver inflammation and tumorigenesis by enhancing IL-6 and TNF expression. Cell. 140. 197-208 (2010).

23. Pinato DJ, et al. A novel and validated prognostic index in hepatocellular carcinoma: the inflammation based index (IBI). J Hepatol. 57, 1013-1020 (2012).

24. Bruix J, Sherman M. Management of hepatocellular carcinoma. Hepatology. 42, 1208-1236 (2005).

25. Bruix J, Sherman M. Management of hepatocellular carcinoma: an update. Hepatology. 53, 1020$1022(2011)$.

26. Llovet JM, Brú C, Bruix J. Prognosis of hepatocellular carcinoma: the BCLC staging classification. Semin Liver Dis. 19, 329-338 (1999).

27. The Liver Cancer Study Group of Japan . The general rules for the clinical and pathological study of primary liver cancer. 6th ed. Tokyo: Kanehara. p26 (2015).

28. Kudo M, Chung H, Osaki Y. Prognostic staging system for hepatocellular carcinoma (CLIP score): its value and limitations, and a proposal for a new staging system, the Japan Integrated Staging Score 
(JIS score). J Gastroenterol. 38, 207-215 (2003).

29. Pugh RN, Murray-Lyon IM, Dawson JL, Pietroni MC, Williams R. Transection of the oesophagus for bleeding oesophageal varices. Br J Surg. 60, 646-649 (1973).

30. Kudo M, et al; Liver Cancer Study Group of Japan. JSH Consensus-Based Clinical Practice Guidelines for the Management of Hepatocellular Carcinoma: 2014 Update by the Liver Cancer Study Group of Japan. Liver Cancer. 3, 458-468 (2014).

31. Kokudo N, et al. Evidence-based Clinical Practice Guidelines for Hepatocellular Carcinoma: The Japan Society of Hepatology 2013 update (3rd JSH-HCC Guidelines). Hepatol Res. 45 (2015). doi: 10.1111/hepr.12464.

32. National Cancer Institute. https://ctep.cancer.gov/protocolDevelopment/adverse_effects.htm. Accessed August 1, 2021.

33. Kaibori M, et al; Liver Cancer Study Group of Japan. Impact of Advanced Age on Survival in Patients Undergoing Resection of Hepatocellular Carcinoma: Report of a Japanese Nationwide Survey. Ann Surg. 269, 692-699 (2019).

34. Motomura T, et al. Neutrophil-lymphocyte ratio reflects hepatocellular carcinoma recurrence after liver transplantation via inflammatory microenvironment. J Hepatol. 58, 58-64 (2103).

35. Heagerty PJ, Zheng Y. Survival model predictive accuracy and ROC curves. Biometrics. 61, 92-105 (2005).

36. Youden W. J. Index for rating diagnostic tests. Cancer. 3, 32-35 (1950).

37. Tada $\mathrm{T}, \mathrm{K}$ et al. Neutrophil-to-lymphocyte ratio is associated with survival in patients with unresectable hepatocellular carcinoma treated with lenvatinib. Liver Int. 40, 968-976 (2020).

38. Kanda Y. Investigation of the freely available easy-to-use software 'EZR' for medical statistics. Bone Marrow Transplant. 48, 452-458 (2013).

\section{Tables}

Table 1. Characteristics of the study patients 


\begin{tabular}{|c|c|c|c|c|}
\hline & Overall & Stratified by CAR & & \\
\hline & $(n=522)$ & $\begin{array}{l}\text { CAR }<0.108 \\
(n=302)\end{array}$ & $\begin{array}{l}C A R \geq 0.108 \\
(n=220)\end{array}$ & $\mathrm{p}_{\text {value }}$ \\
\hline Age $^{\star}$ (years) & $\begin{array}{l}73.0(68.0- \\
79.0)\end{array}$ & $\begin{array}{l}74.0(69.0- \\
80.0)\end{array}$ & $\begin{array}{l}72.0(66.0- \\
78.0)\end{array}$ & 0.039 \\
\hline Sex (female/male) & $112 / 410$ & $73 / 229$ & $39 / 181$ & 0.084 \\
\hline ECOG-PS $(0 / 1 / 2 / 3)$ & $397 / 108 / 16 / 1$ & $234 / 59 / 8 / 1$ & $163 / 49 / 8 / 0$ & 0.668 \\
\hline Body mass index $\left(\mathrm{kg} / \mathrm{m}^{2}\right)$ & $\begin{array}{l}23.1(20.9- \\
25.5)\end{array}$ & $\begin{array}{l}23.7(21.3- \\
25.4)\end{array}$ & $\begin{array}{l}22.6(20.6- \\
25.5)\end{array}$ & 0.120 \\
\hline $\begin{array}{l}\text { Etiology of HCC } \\
\text { (hepatitis } B / C / \text { non-B, non-C) }\end{array}$ & $74 / 217 / 231$ & $44 / 142 / 116$ & $30 / 75 / 115$ & 0.005 \\
\hline Albumin $(\mathrm{g} / \mathrm{dL})^{\star}$ & $3.7(3.3-4.0)$ & $3.9(3.6-4.1)$ & $3.5(3.0-3.8)$ & $<0.001$ \\
\hline Total bilirubin (mg/dL)* & $0.7(0.5-1.0)$ & $0.7(0.6-1.0)$ & $0.8(0.5-1.1)$ & 0.692 \\
\hline $\mathrm{CRP}(\mathrm{mg} / \mathrm{dL})$ * & $\begin{array}{l}0.28(0.11- \\
0.89)\end{array}$ & $\begin{array}{l}0.12(0.06- \\
0.22)\end{array}$ & $\begin{array}{l}1.10(0.66- \\
2.39)\end{array}$ & $<0.001$ \\
\hline $\mathrm{CAR}^{*}$ & $\begin{array}{l}0.079(0.027- \\
0.254)\end{array}$ & $\begin{array}{l}0.032(0.015- \\
0.058)\end{array}$ & $\begin{array}{l}0.322(0.183- \\
0.701)\end{array}$ & $<0.001$ \\
\hline a-fetoprotein $(\mathrm{ng} / \mathrm{mL}) \star$ & $\begin{array}{l}30.0(5.6- \\
691.1)\end{array}$ & $\begin{array}{l}24.1(5.3- \\
390.3)\end{array}$ & $\begin{array}{l}44.4(6.3- \\
1322.8)\end{array}$ & 0.090 \\
\hline Child-Pugh score $(5 / 6 / \geq 7)$ & $302 / 206 / 14$ & $211 / 87 / 4$ & $91 / 119 / 10$ & $<0.001$ \\
\hline $\begin{array}{l}\text { Macroscopic vascular invasion } \\
\text { (yes/no) }\end{array}$ & $115 / 407$ & $55 / 247$ & $60 / 160$ & 0.018 \\
\hline Extrahepatic spread (yes/no) & $192 / 330$ & $99 / 203$ & $93 / 127$ & 0.028 \\
\hline BCLC stage $(0 / A / B / C / D)$ & $4 / 12 / 218 / 287 / 1$ & $4 / 9 / 134 / 154 / 1$ & 0/3/84/133/0 & 0.064 \\
\hline $\begin{array}{l}\text { TNM LCSGJ } 6^{\text {th }} \text { edition } \\
(\mathrm{I} / \mathrm{II} / \mathrm{III} / \mathrm{IV})\end{array}$ & $5 / 89 / 203 / 225$ & $5 / 60 / 125 / 112$ & $0 / 29 / 78 / 113$ & 0.002 \\
\hline JIS score $(0 / 1 / 2 / 3 / 4)$ & $5 / 88 / 197 / 226 / 6$ & $5 / 60 / 123 / 112 / 2$ & $0 / 28 / 74 / 114 / 4$ & 0.001 \\
\hline $\begin{array}{l}\text { History of sorafenib } \\
\text { therapy (yes/no) }\end{array}$ & $124 / 398$ & $55 / 247$ & $69 / 151$ & 0.001 \\
\hline Follow-up duration* (months) & $13.3(7.0-22.6)$ & $16.9(9.5-25.2)$ & $9.6(5.2-17.5)$ & $<0.001$ \\
\hline Therapeutic response & & & & 0.134 \\
\hline Complete response & $24(5.0 \%)$ & $16(5.7 \%)$ & $8(4.0 \%)$ & \\
\hline Partial response & $178(37.0 \%)$ & $113(40.4 \%)$ & 65 (32.3\%) & \\
\hline
\end{tabular}




\begin{tabular}{|lllll|}
\hline Stable disease & $189(39.3 \%)$ & $106(37.9 \%)$ & $83(41.3 \%)$ & \\
\hline Progressive disease & $90(18.7 \%)$ & $45(16.1 \%)$ & $45(22.4 \%)$ & \\
\hline Not evaluated & 41 & 22 & 19 & \\
\hline Overall response rate & $42.0 \%$ & $46.1 \%$ & $36.3 \%$ & 0.039 \\
\hline Disease control rate & $81.3 \%$ & $83.9 \%$ & $77.6 \%$ & 0.097 \\
\hline
\end{tabular}

*Data expressed as medians (interquartile range).

ECOG-PS, Eastern Cooperative Oncology Group performance status; HCC, hepatocellular carcinoma; CRP, C-reactive protein; CAR, C-reactive protein to albumin ratio; BCLC, Barcelona Clinic Liver Cancer; TNM LCSGJ $6^{\text {th }}$ : tumor node metastasis stage according to the $6^{\text {th }}$ edition of the Liver Cancer Study Group of Japan guidelines; JIS, Japan Integrated Staging.

\section{Table 2. Overall survival analysis}


$\mathrm{HR}$, hazard ratio; $\mathrm{Cl}$, confidence interval; ECOG-PS, Eastern Cooperative Oncology Group Performance Status; CAR, C-reactive protein to albumin ratio.

Table 3. Progression-free survival analysis 
Univariate analysis

$\mathrm{HR} \quad 95 \% \mathrm{Cl}$
Multivariate analysis

$\begin{array}{llll}p & H R & 95 \% \mathrm{Cl} & \mathbf{p}_{\text {value }}\end{array}$

Age (years)

$<75(\mathrm{n}=303)$

$1 \quad 0.841-$

$\geq 75(\mathrm{n}=219)$

1.038

1.280

0.731

1

$0.885-$

1.372

0.385

1.102

\section{Sex}

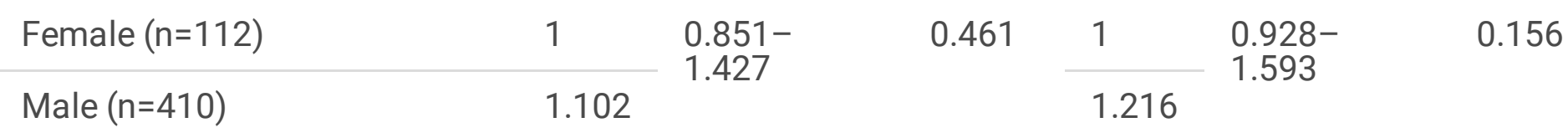

\section{ECOG-PS}

$0(n=397)$

$\geq 1(n=125)$

$\begin{array}{ll}1 & 0.978- \\ 1 & 1.606\end{array}$

0.074

1

0.937-

1.570

0.143

\section{Etiology}

Viral hepatitis $(n=291)$

Non- $B$, non- $C(n=231)$

1.253

1.606

\subsection{3}

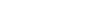

\section{a-fetoprotein $(\mathrm{ng} / \mathrm{mL})$}

$<400(\mathrm{n}=373)$

$\geq 400$ ( $n=149)$

$\begin{array}{ll}1 & 0.625- \\ 0.772 & 0.953\end{array}$

0.772

0.016

$0.583-$

0.905

0.004
0.726

\section{Macroscopic vascular}

invasion

\begin{tabular}{|c|c|c|c|c|c|}
\hline Absent $(n=407)$ & 1 & \multirow{2}{*}{$\begin{array}{l}0.765- \\
1.264\end{array}$} & \multirow[t]{2}{*}{0.895} & 1 & \multirow{2}{*}{$\begin{array}{l}0.687- \\
1.172\end{array}$} \\
\hline Present $(n=115)$ & 0.983 & & & & \\
\hline
\end{tabular}

\section{Extrahepatic spread}

Absent $(n=330)$

Present $(n=192)$

History of sorafenib therapy

No $(n=398)$

Yes $(n=124)$

\section{CAR}

$<0.108(n=302)$

$\begin{array}{ll}1 & 0.994- \\ 1.243 & 1.555\end{array}$

0.057

1

1.170

0.186 1.475

$0.921-$
1.404

1.137
0.232

1

1.143
$0.918-$

1.423

0.233 
HR, hazard ratio; Cl, confidence interval; ECOG-PS, Eastern Cooperative Oncology Group performance status; CAR, C-reactive protein to albumin ratio.

\section{Figures}

Figure 1

(a)

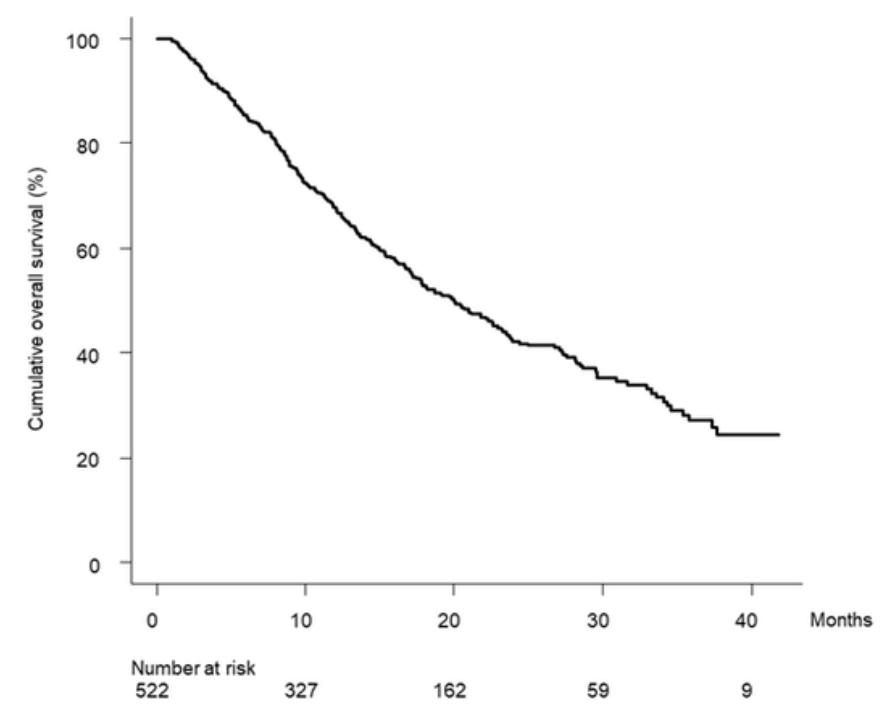

(b)

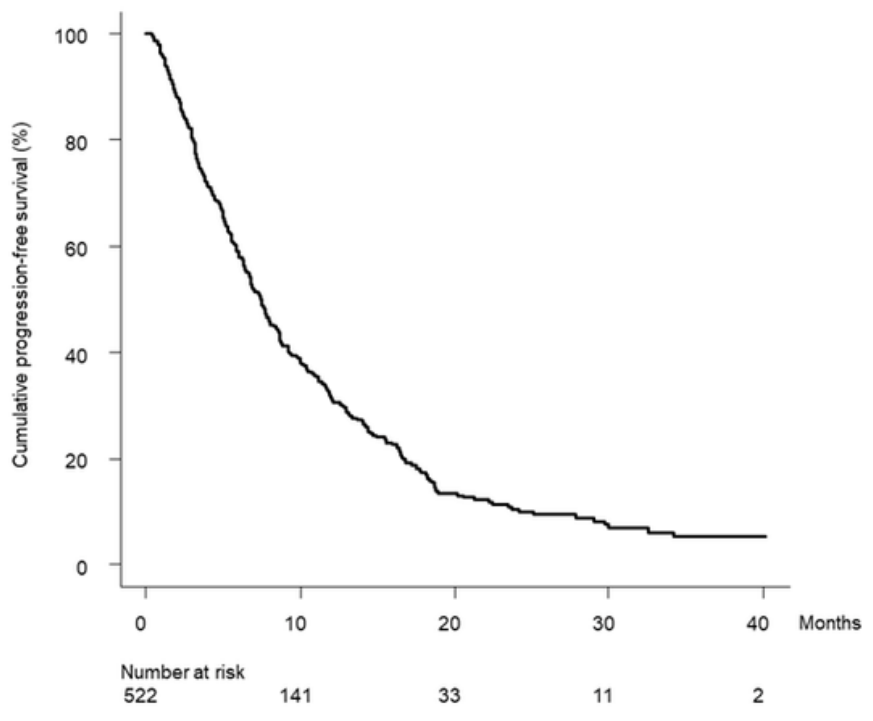

\section{Figure 1}

a. Cumulative overall survival curve Cumulative overall survival at $6,12,18,24,30$, and 36 months was $85.4 \%, 67.6 \%, 52.7 \%, 42.2 \%, 35.2 \%$, and $27.1 \%$, respectively. b. Cumulative progression-free survival curve Cumulative progression-free survival at $3,6,9,12,15$, and 18 months was $80.2 \%, 59.1 \%, 41.3 \%, 31.4 \%$, $24.1 \%$, and $17.4 \%$, respectively. 
Figure 2

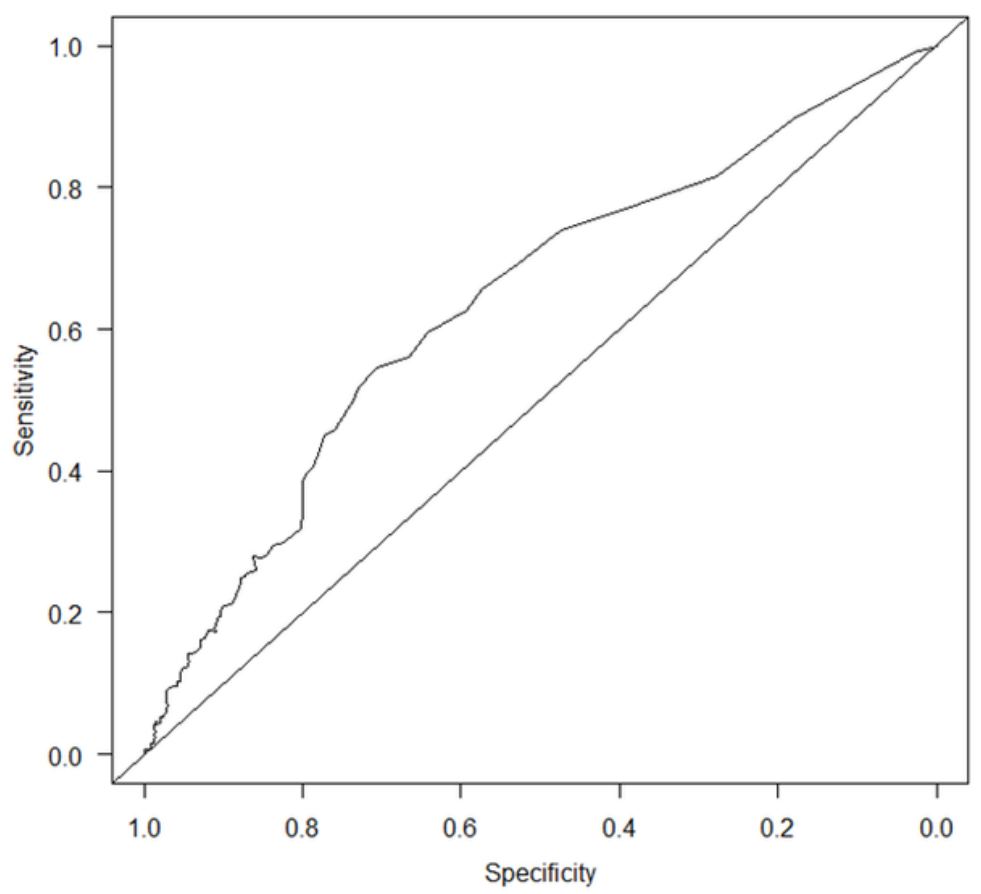

Figure 2

Time-dependent ROC curve of CAR for overall survival at 20 months after the start of follow-up The area under the ROC curve was 0.638 . Sensitivity and specificity using the CAR cutoff value of 0.108 according to the Youden index were $54.7 \%$ and $71.0 \%$, respectively. ROC, receiver operating characteristic; CAR, Creactive protein to albumin ratio. 
Figure 3

(a)

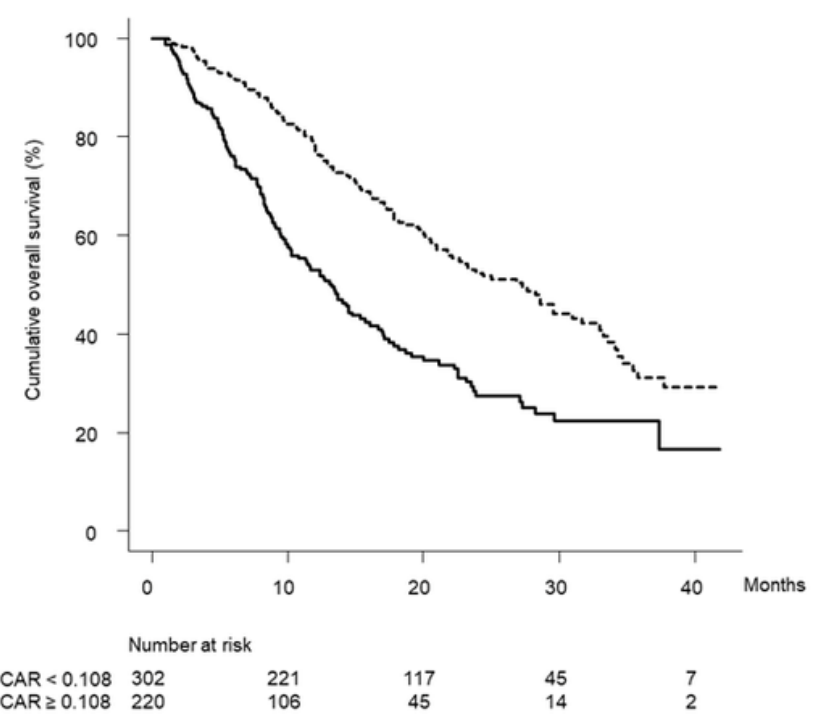

(b)

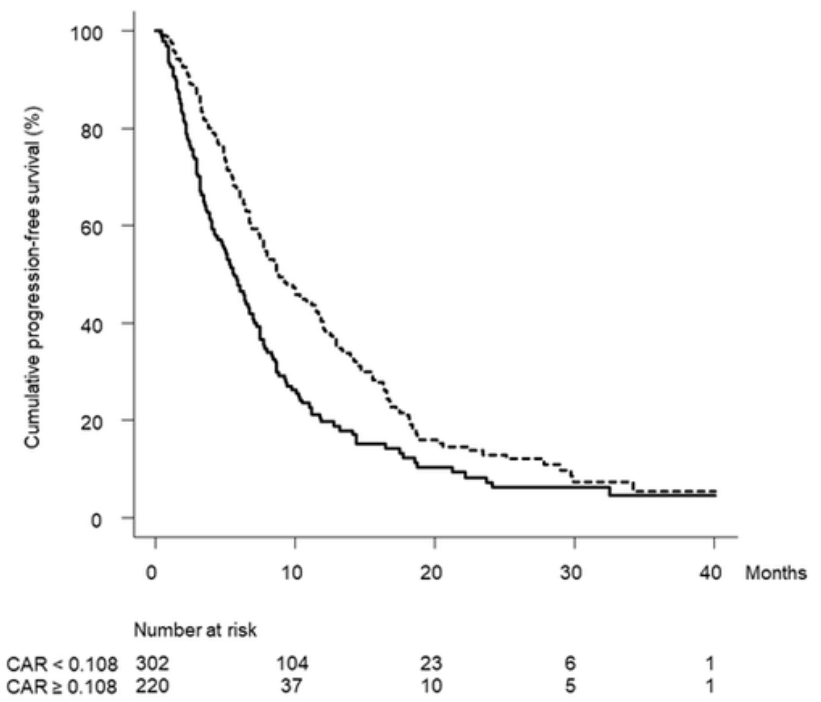

\section{Figure 3}

a. Cumulative overall survival curves stratified by CAR Cumulative overall survival at $6,12,18,24,30$, and 36 months was $92.2 \%, 78.0 \%, 63.2 \%, 53.0 \%, 44.1 \%$, and $31.1 \%$ in patients with low CAR (<0.108) (dotted line) and $76.0 \%, 53.1 \%, 37.6 \%, 27.6 \%, 22.3 \%$, and $22.3 \%$ in patients with high CAR ( $\geq 0.108)$ (solid line), respectively ( $p<0.001$, log-rank test). b. Cumulative progression-free survival curves stratified by CAR Cumulative progression-free survival at $3,6,9,12,15$, and 18 months was $87.0 \%, 67.0 \%, 49.4 \%, 39.2 \%$, $29.9 \%$, and $20.9 \%$ in patients with low CAR (<0.108) (dotted line) and 70.5\%, 47.7\%, 29.2\%, 19.7\%, 15.2\%, and $12.4 \%$ in patients with high CAR $(\geq 0.108)$ (solid line), respectively $(p<0.001$, log-rank test). CAR, Creactive protein to albumin ratio. 
Figure 4
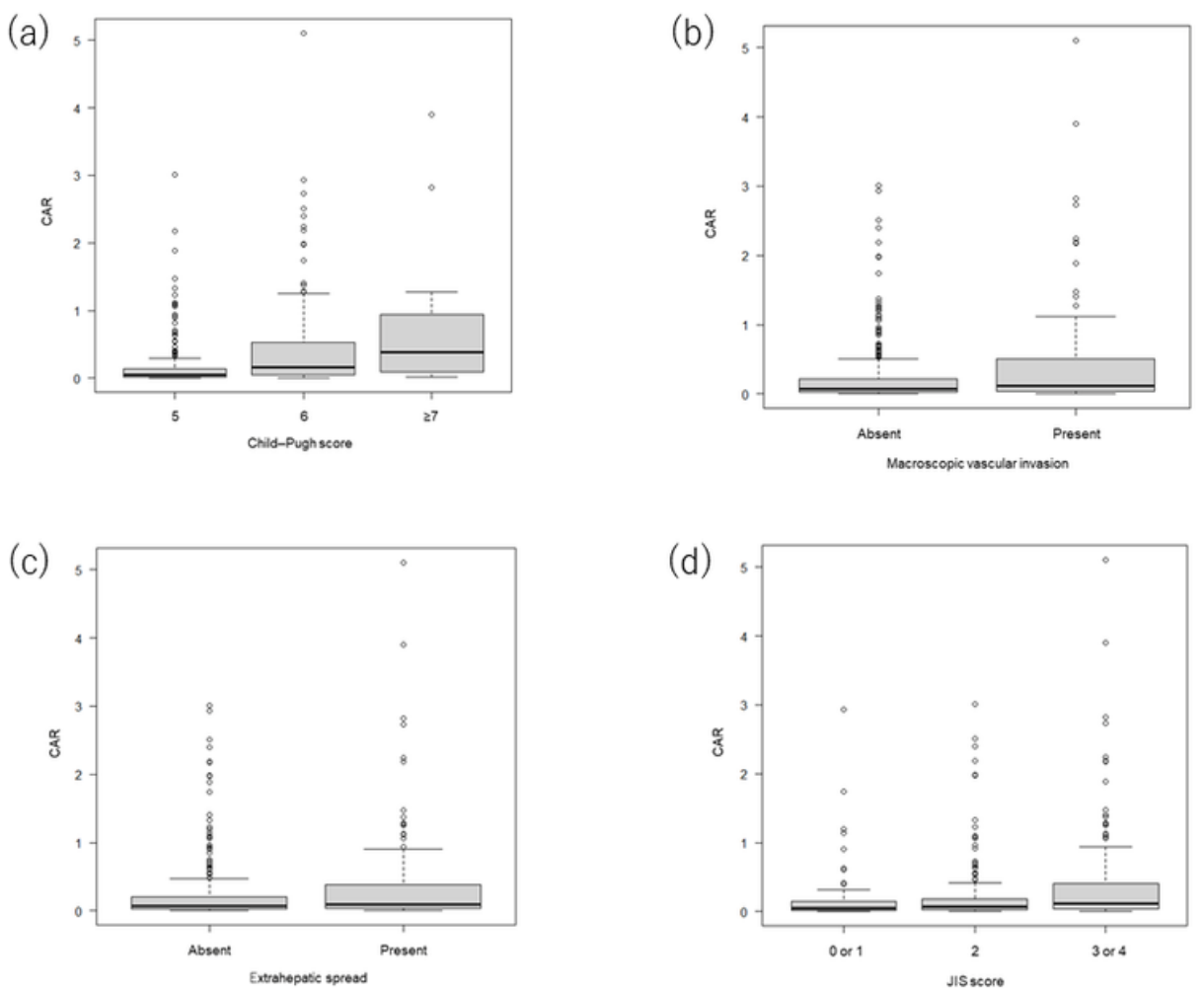

\section{Figure 4}

Relationship between clinical markers and CAR a. Relationship between Child-Pugh score and CAR CAR values were 0.049 (0.020-0.136), 0.160 (0.047-0.527), and 0.381 (0.133-0.922) in patients with ChildPugh score of $5(n=302), 6(n=206)$, and $\geq 7(n=14)$, respectively ( $p<0.001$, Jonckheere-Terpstra test). b. Relationship between the presence or absence of macroscopic vascular invasion and CAR CAR values were $0.074(0.025-0.222)$ and $0.120(0.038-0.505)$ in patients with $(n=407)$ and without $(n=115)$ macroscopic vascular invasion, respectively ( $p=0.001$, Mann-Whitney U-test). c. Relationship between the presence or absence of extrahepatic spread and CAR CAR values were $0.072(0.025-0.209)$ and $0.097(0.036-0.384)$ in patients with $(n=330)$ and without $(n=192)$ extrahepatic spread, respectively $(p=0.008$, Mann-Whitney U-test). $d$. Relationship between JIS score and CAR CAR values were 0.045 (0.015-0.152), $0.074(0.026-0.188)$, and $0.116(0.036-0.409)$ in patients with JIS score of 0 or $1(n=93)$, $2(n=197)$, and 3 or $4(n=232)$, respectively ( $p<0.001$, Jonckheere-Terpstra test). The box represents the interquartile range. The line through the box indicates the median. The bottom error bar indicates the 25th percentile $-1.5 \times$ interquartile range and the top error bar indicates the 75 th percentile $+1.5 \times$ interquartile range. CAR, C-reactive protein to albumin ratio; JIS, Japan Integrated Staging. 
Figure 5

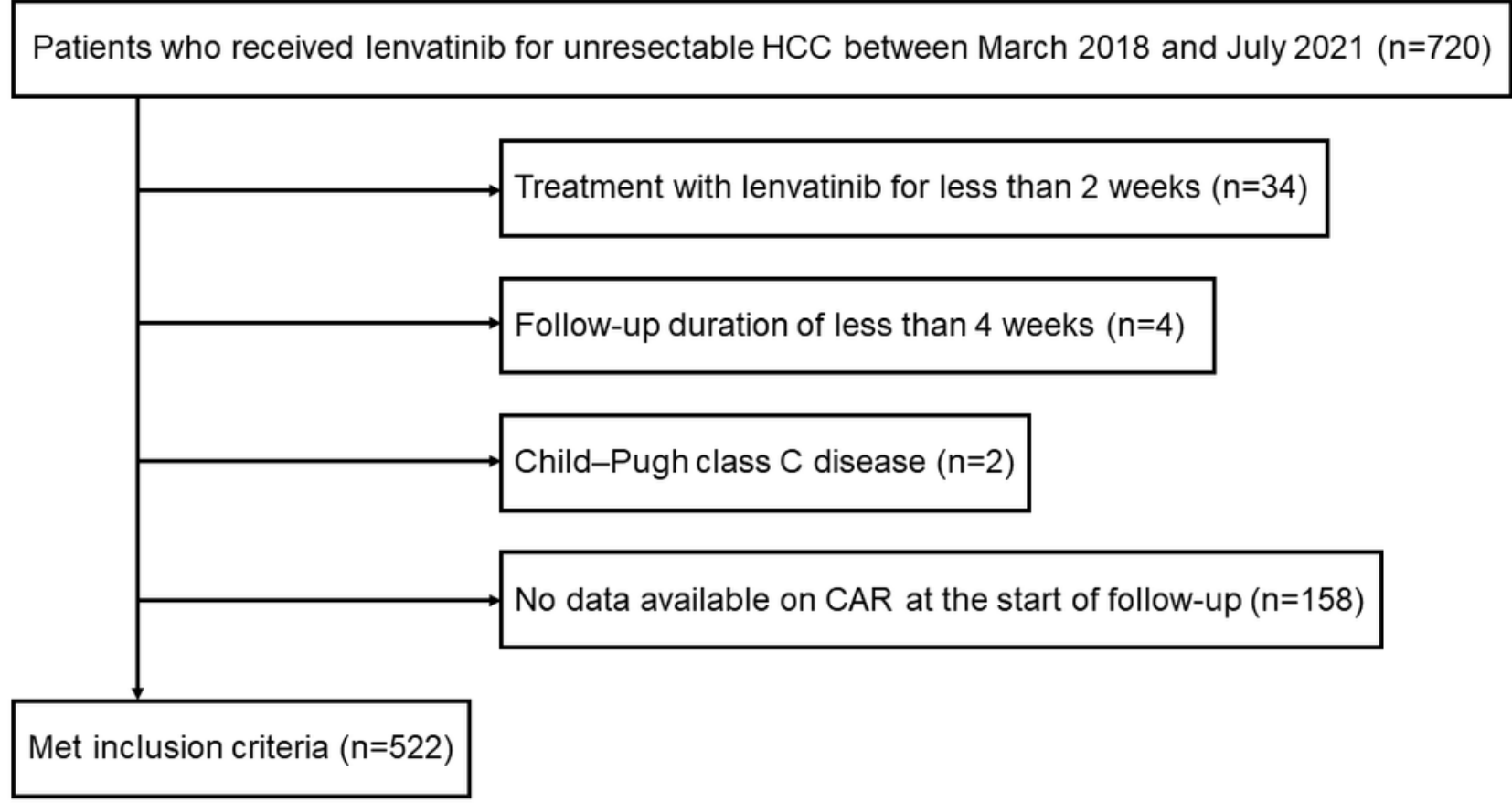

\section{Figure 5}

Flowchart of the patient selection process HCC, hepatocellular carcinoma; CAR, C-reactive protein to albumin ratio. 